\title{
Fine Needle Aspiration Cytological Diagnosis of Thyroid Nodule with Its Clinical Correlation
}

\section{Q Hassan ${ }^{1}$, M A Hasanat ${ }^{2}$, M Fariduddin², M S Emran ${ }^{2}$, Marufa-Mustari' ${ }^{2}$ Sharmin-Jahan ${ }^{2}$, Nusrat-sultana $^{2}$, Hurjahan-Banu' ${ }^{2}$, Sunil K Biswas ${ }^{3}$, M Rafiqul Alam ${ }^{3}, \quad$ M Kamal $^{4}$}

${ }^{1}$, Registrar ${ }^{2}$, Professor and Chairman, ${ }^{2}$, Endocrine Fellow ${ }^{3}$, Associate Professor ${ }^{2}$, Student ${ }^{2}$, Resident, ${ }^{2}$, Medical Officer \& Resident ${ }^{3}$, Associate Professor ${ }^{2}$, Medical Officer ${ }^{4}$, Professor and Chairman ${ }^{2}$, Associate Professor,

\begin{abstract}
:
Background: Nodular goiter is common in Bangladesh. Thyroid nodules are important for their malignant potential especially the solitary and cold ones and when functionally euthyroid. Objectives: This study was designed to investigate the frequency of malignancy and cellular aberration detected by fine needle aspiration cytology (FNAC) in euthyroid nodules and its correlation with clinical findings. Methods: Subjects with nodular goiter attending Endocrine out patient department [ $\mathrm{n}=150$, nonpregnant, age (mean \pm SD): $37 \pm 12$ years; sex (male: female): $21: 129]$ were recruited for this study. All subjects underwent clinical risk stratification, estimation of FT4 and TSH as well as ultrasonogram (USG) and isotope scan of thyroid. Thyroid nodules were categorized into malignant, suspicious, benign and indeterminant on the basis of cellular character by FNAC. Statistical analysis was done by Chi-square and multiple regression analysis. Results: Patients were mostly females $(86 \%)$ and $4.7 \%$ had family history of thyroid problems. Some had recent changes of size $(14.7 \%)$, pain in the nodule $(4 \%)$ and dysphagia (6\%). Nodules were solitary in $45.3 \%$ and the rest $(54.7 \%)$ had multinodular goiter. Enlarged regional lymph node was found in $12.7 \%$ patients. About $41 \%$ were partially-cold followed by cold nodules $(26.7 \%)$, patchy $(16.7 \%)$, isoform $(12 \%)$ and hot $(4 \%)$ by isotope scan. Frequency of malignant $(10 \%)$ character was highest in cold nodules followed by uniform $(5.6 \%)$, patchy $(4.0 \%)$ and partially cold (1.6\%) while none in hot nodules; which were $22.5 \%, 11.1 \%, 4.0 \%, 9.8 \%$ and $16.7 \%$ respectively for suspicious nodules. About $17 \%$ showed cellular aberration and $4.7 \%$ were clearly malignant, whereas $124(82.7 \%)$ were benign. Of the malignant, 4 were solitary and 3 were multinodular; which were 10 and 9 among the suspicious ones. A significant number (77\%, 20 out of 26) among the malignant/suspicious nodules fell into moderate to high risk category $(\chi 2=22.861, \mathrm{p}<0.001)$, while $23.1 \%$ of the FNAC proven malignant/suspicious nodules were of low risk category. Enlarged lymph nodes $(\mathrm{p}<0.001)$, increased diameter of nodules of $>4 \mathrm{~cm}(\mathrm{p}=0.039)$ and recent changes in nodular size $(\mathrm{p}=0.042)$ were independently and significantly related to cellular aberration. Conclusions: FNAC is a useful tool for cellular diagnosis of thyroid nodules. Clinical suspicion for malignancy strongly correlates with the FNAC findings. But a good number of clinically low risk categories would escape malignant cellular character unless FNAC is done.
\end{abstract}

Key words: FNAC, Thyroid nodule and goiter.

[BSMMUJ 2013; 6(2) : 108-115]

\section{Introduction}

Nodular goiter is a common thyroid problem, particularly among women. The prevalence of palpable thyroid nodules in the United States has been estimated to be about $4 \%$ of the adult population, with a female:male ratio

Address for Correspondence: Dr. M A Hasanat, MBBS, M.Phil, MD Associate Professor, Department of Endocrinology BSMMU, Dhaka. Tel: 01711670735 (cell) of $4: 1$. It is common as with the prevalence of $1-7 \%$ in general population on routine clinical examination and however, up to $50 \%$ at autopsy ${ }^{1,2}$. Nodular thyroid disease is frequent in Bangladesh. According to the thyroid clinic of BSSMU reports $32.74 \%$ patients present with solitary thyroid nodules ${ }^{3}$. A high prevalence (about $50 \%$ ) of microscopic nodule is also reported by other investigators in some parts of the world ${ }^{4}$. Nodular goiter is very common in the region of dietary iodine deficiency 
and in goitrous area the frequency of single thyroid nodule is higher ${ }^{5,6}$.

A thyroid nodule is a small ill defined lump or swelling of abnormal tissue within the thyroid gland, which results from a process of cyclical hyperplasia and involution (Fig-1). The nodule may be either solitary or multiple. Usually the pathogenesis of nodule formation appears to be iodine - deficiency induced hyperplasia followed by lakes of colloid; Over time repetition of this process leads to overall glandular enlargement with nonfunctioning colloid nodules, the dominant histopathological features ${ }^{7}$. The nodule may regress spontaneously; the role of thyroxine therapy to reduce the nodule size is inconclusive ${ }^{8}$.

Solitary thyroid nodules are important for their malignant potential. Cold nodules are very important clinically because there is maximum chance of developing cancer from cold nodules 9 . Although thyroid nodules are common, thyroid cancer is a relatively rare condition, with an annual incidence of approximately 7.5 per 100000 populations ${ }^{10}$.

The vast majority (95\%) of thyroid nodules is benign, and it is important to identify those which are likely to be malignant. Occasionally, especially in children, enlarged cervical lymph nodes are the first sign of the disease, although on careful examination a small thyroid nodule can often be felt. Rarely distant metastasis in lung or bone is the first sign of thyroid cancer. The incidence of carcinoma in solitary cold nodule is about $5-10 \%$ and $90 \%$ $95 \%$ or more are benign. The probability of cancer in a hot nodule is less than cold nodule ${ }^{10}$.

FNAC has been established as the investigation of choice in discrete thyroid swellings. It is simple and easy to perform in outpatient department and also cost effective. It has high degree of sensitivity and specificity (95\%) in context to histopathological categories of papillary carcinoma, medullary carcinoma, anaplastic carcinoma, thyroiditis, colloid nodules and lymphoma ${ }^{11,12}$. Other diagnostic modalities which are not rich enough in discriminating benign from malignant tumors.

Medical guidelines for clinical practice as set forth by the
American thyroid Association \& National Comprehensive Cancer Network states that FNA should be used as the initial diagnostic test because of its superior diagnostic reliability and cost effectiveness ${ }^{13}$. Nevertheless, like any other test FNAC has its limitations. The reported pitfalls are those related to specimen adequacy, sampling techniques, the skill of the physician performing the aspiration, the experience of the pathologist interpreting as well as Hurthle cell adenoma or carcinoma $1^{4,15,16}$.

The thyroid nodule is an elusive problem for the clinician, no single historical or physical examination findings provide overwhelming evidence in favor of a malignant disease. Likewise, no single factor eliminates the possibility of cancer. The non-specificity and non-sensitivity of the clinical history and physical examinations should not, however, be interpreted to mean that they are worthless. Some historical and physical examinations features are obviously more suggestive of a malignant process than others. The present study would hopefully highlight on the correlations of clinical findings of thyroid malignancy with the FNAC diagnosis, it also focus next plan for study at mass scale to settle the issue of thyroid malignancy among the frequently observed thyroid swelling in our country.

Clinical features associated with a low risk of thyroid cancer include; female sex, a soft nodule on physical examination and the presence of a multinodular goiter. Individual with high risk of thyroid cancer include children, young adults and males. Solitary firm or dominant nodule that is clearly different from the rest of the gland signifies an increased risk of malignancy; vocal cord paralysis, enlarged ipsilateral lymph nodes and suspected metastasis are strongly suggestive of malignancy ${ }^{10}$. Hamming et al have provided interesting data on the correlation between clinical factors and histology of resected thyroid nodules. If a given patient had two or more clinical features of high clinical suspicion the chance of cancer was $100 \%{ }^{17}$.

In this study, the clinical features were rated as having high, moderate or low clinical suspicion for thyroid cancer. Patients who had a clinical factor with high and moderate suspicion for cancer had a 77 percent incidence 
suspicion for thyroid cancer only had 23 percent incidence of thyroid cancer.

\section{Fine Needle Aspiration Cytology (FNAC)}

Thyroid conditions which can be diagnosed by FNAC are benign lesions include colloid nodule, cystic nodule and thyroiditis. Malignant lesions include papillary carcinoma, medullary carcinoma, anaplastic carcinoma and Lymphoma etc. Suspicious lesions which includes follicular carcinoma, follicular adenoma and undiagnosed lesions. All patients with a palpable thyroid nodule, however, should undergo US examination. US-FNA is suggested for nodules $<10 \mathrm{~mm}$ only if clinical information or US features are suspicious ${ }^{18}$. Fine-needle aspiration cytology has high positive predictive value for thyroid cancer, enabling us to 'rule-in' malignant lesions with confidence ${ }^{19}$. The efficacy of FNAC has been evaluated in multiple series. In a study of 61 patients, Tollin and colleagues have examined the risk of malignancy in thyroid nodules occurring in multinodular non toxic goiter, demonstrating an overall malignancy rate of approximately $5 \%{ }^{20}$. Analysis of sensitivity reveals that the procedure is extremely sensitive with rates between 83-90 percent. Likewise the specificity has ranged between 70-90 percent ${ }^{21}$. Lowhager and his colleagues ${ }^{22}$ believe that nearly 80 percent of the patients with thyroid nodule can be spared surgical exploration. FNAC of thyroid nodule is considered most cost effective and reliable diagnostic procedure if appropriate expertise available. The cytopathologic results are classified as follows;

a) Benign (negative): A benign (negative) cytodiagnosis is the most common finding, accounting for approximately $70 \%$ of results ${ }^{18}$. Benign cytology includes benign colloid nodule, macro follicular adenoma, lymphocytic thyroiditis, granulomatous thyroiditis, or benign cyst. The most common benign diagnosis is "colloid nodule". Which may be found in the setting of a normal thyroid, a benign thyroid, a benign nodule, a multinodular goiter, or a macrofollicular adenoma.

b) Malignant (positive): Malignant (positive) results can frequent malignant lesion encountered is papillary thyroid carcinoma (PTC). Aspirates of PTC are characterized by increased cellularity; tumor cells arranged in sheets and papillary cell groups; and typical nuclear abnormalities, including intranuclear holes and grooves. Medullary carcinoma is characterized by hyper cellularity, tumor cells that are notably noncohesive, and nuclei that are hyperchromatic and located at the end of an elongated cell body. Other malignant lesions include primary anaplastic carcinoma and high-grade metastatic cancers.

c) Suspicious: It results from specimen for which a definite cytological diagnosis cannot be made ${ }^{18}$. Often these include follicular neoplasms, Hurthle cell neoplasms or lymphoma. Follicular neoplasms appear as hypercellular specimens with monotony of cells, microfollicular arrangement and diminished or absent colloid. Hurthle cell neoplasm is diagnosed in an aspirate that is almost entirely Hurthle cells.

d) Inadequate specimen: Aspirates are those with too few epithelial cells. Commonly, inadequate smears are collected from cystic lesions that are leaking fluid and degenerative foam cells, too much blood, and excessive air-drawing and insufficient experience with FNA techniques.

This study was designed to investigate the frequency of malignancy and cellular aberration detected by fine needle aspiration cytology (FNAC) in euthyroid nodules and its correlation with clinical findings.

\section{Methods:}

The cross sectional study was carried out in the Endocrinology outpatient department of Bangabandhu Sheikh Mujib Medical University (BSMMU), Dhaka from July 2010 to June 2011. Subjects with nodular goiter attending Endocrine out patient department [ $\mathrm{n}=150$, none pregnant, age (mean $\pm \mathrm{SD}$ ): $37 \pm 12$ years; sex (male: female): 21:129] were recruited for this study.

The particulars of the patients and clinical data were recorded in a pre-designed data-sheet. The whole proce- 
dure was explained to the patient and written consent taken. Clinical risk stratification was done as: High suspicion: family history of medullary thyroid cancer (MEN), rapid / recent growth of the nodule, fixation to adjacent structure, vocal cord paralysis, enlarged regional lymph nodes, distant metastasis, biochemically euthyroid, sonographically - loss of halo sign, irregular margin, micro calcification, mixed cystic, chaotic vascularity, scintiscan - cold nodule; Moderate suspicion: history of irradiation, age $<20$ years, age $>60$ years, dubious fixation, diameter $>4 \mathrm{~cm}$, partially cystic; Low suspicision: others. All patients were assessed for serum FT4 and TSH. Scintigraphic examination of the thyroid gland was carried out in each patient with Technetium in Nuclear Medicine department ${ }^{99}$. In each case ultrasonographic examination was performed by same machine. In each case FNAC was performed and aspiration note was noted. Fine needle aspiration cytology was performed on the patient in supine position, neck fully extended by a pillow underneath the shoulders. A 23 gauge needle attached with $5 \mathrm{ml}$ syringe was used to collect the tissue sample. Multiple passes was made through the centre and the periphery of the nodules. A cytopathology technician was present during the aspirations, who prepared the slides. The cytopathologic results are classified as follows; 1) Benign 2) Malignant 3) Suspicious and 4) Indeterminate on the basis of cellular character.

For statistical analysis Chi-square test was done. Multiple regression analysis was done to see the independent significance of various factors for thyroid nodular malignancy. Prior to the commencement of this study, the research protocol was approved by ethical review committee. The study was explained to the patients in easily understandable la guage and then informed consent was taken from each patient.

\section{Results:}

The results showed that patients were mostly females $(86 \%)$. As described in Table-I, a few had recent changes of size $(14.7 \%)$, pain in the nodule $(4 \%)$ and dysphagia $(6 \%)$. In 68 subjects $(45.3 \%)$ nodules were solitary; the rest $82(54.7 \%)$ had multinodular goiter. Enlarged regional lymph node was found in 19 (12.7\%) patients (Table-II).
Scintigraphy results showed $61(41 \%)$ were partially-cold followed by $40(26.7 \%)$ had cold nodules, $25(16.7 \%)$ patchy, isoform $18(12 \%)$ and $6(4 \%)$ had hot nodule (Table-III).

Frequency of malignancy $4(10 \%)$ was highest in cold nodules followed by isoform $1(5.6 \%)$, patchy $1(4.0 \%)$ and partially cold $1(1.6 \%)$, while none in hot nodules; however among the suspicious cytology 9 (22.5\%) had cold nodules, $6(11.1 \%)$ had partially cold nodules, $2(4.0 \%)$ had isoform, $1(9.8 \%)$ had patchy nodule and 1 $(16.7 \%$ ) had hot nodule (Table-IV). As shown in Table-V, USG revealed $33(22 \%)$ solitary, $79(52.7 \%)$ multinodular, $30(20 \%)$ mixed and $8(5.3 \%)$ cystic nodules.

Twenty six $(17 \%)$ of the nodules showed cellular aberration (malignant and suspicious) and 7 (4.7\%) were clearly malignant whereas $124(82.7 \%$ ) were benign (Fig-2). Of the malignant, 4 subjects had solitary and 3 had multinodular goiter. Among the suspicious cytology group (19 patients) 10 had solitary and rest 9 had multinodular goiter (Table-VI). Among 26 FNAC proven aberrant cytology (malignant and suspicious) $20(77 \%)$ fell into high to moderate risk category $(\chi 2=22.861, p<0.001)$, while $23.1 \%$ of the FNAC proven malignant/suspicious nodules were of low risk category Table-VII). Enlarged lymph nodes $(\mathrm{p}<0.001$ ), increased diameter of nodules of more than $4 \mathrm{~cm}(\mathrm{p}=0.039)$ and recent changes in nodular size $(\mathrm{p}=0.042$,) were independently and significantly related to cellular aberration Table-VIII). Two of the patients had all the three characteristics and both of them had cellular aberration (Table-IX).

Table I

Clinical characteristics $(n=150)$

\begin{tabular}{lc}
\hline Clinical feature & $(\mathrm{n} \%)$ \\
\hline Palpable nodule & $150(100)$ \\
Recent change of size & $22(14.7)$ \\
Pain & $6(4)$ \\
Dysphagia & $9(6)$ \\
Dyspnea & $\mathrm{Nil}$ \\
Voice change & $1(0.7)$ \\
\hline
\end{tabular}

Within parenthesis are percentages over grand total 
Table - II

Characteristics of the thyroid nodules $(N=150)$

Items

$(\mathrm{n} \%)$

Location of nodule

$\begin{array}{lc}\text { Right lobe } & 38(25.3) \\ \text { Left lobe } & 41(27.3) \\ \text { Isthmus } & 2(1.3) \\ \text { Bilateral } & 69(46)\end{array}$

Number of the nodule

$$
\begin{aligned}
& \text { Solitary nodule } \\
& \text { Multi nodule }
\end{aligned}
$$

Over lying skin change normal

Tenderness of the nodule

Consistency

\begin{tabular}{cc} 
Fard & Nil \\
Firm & $149(99.3)$ \\
Soft & $1(.7)$ \\
Movement on deglutition & mobile \\
Enlargement of regional lymph nodes & $19(12.7)$ \\
\hline within parenthesis are percentages over grand total \\
\multicolumn{2}{c}{ Table -III }
\end{tabular}

Scan category

Uniform

Partially cold

Cold nodule

Hot nodule

Patchy

within parenthesis are percentages over grand total
Table - IV

Cellular character and scan types of nodular goiter

\begin{tabular}{lcccc}
\hline Scan & \multicolumn{2}{c}{$\begin{array}{c}\text { category } \\
\text { Cellular character }\end{array}$} & \multicolumn{2}{c}{$\begin{array}{c}\text { Total } \\
(\mathrm{n}=150)\end{array}$} \\
\cline { 2 - 3 } & Benign & Malignant & Suspicious & \\
\hline Uniform & $15(83.3)$ & $1(5.6)$ & $2(11.1)$ & 18 \\
Partially cold & $54(88.4)$ & $1(1.6)$ & $6(9.8)$ & 61 \\
Cold nodule & $27(67.5)$ & $4(10.0)$ & $9(22.5)$ & 40 \\
Hot nodule & $5(83.3)$ & 0 & $1(16.7)$ & 6 \\
Patchy & $23(92.0)$ & $1(4.0)$ & $1(4.0)$ & 25 \\
\hline
\end{tabular}

Within parenthesis are percentages over row total

Table-V

USG character of the thyroid nodules

\begin{tabular}{lc}
\hline Character & $(\mathrm{n} \%)$ \\
\hline Solitary Nodule & $33(22)$ \\
Multi nodular goiter & $9(52.7)$ \\
Mixed & $30(20)$ \\
Cystic & $8(5.3)$ \\
\hline
\end{tabular}

Within parenthesis are percentages over grand total

Table-VI

Cellular character of the nodules $(n=150)$

\begin{tabular}{lc}
\hline Character & $(\mathrm{n}, \%)$ \\
\hline Benign & $124(82.7)$ \\
Malignant & $7(4.7)^{*}$ \\
Suspicious & $19(12.7) \#$ \\
Indeterminate & 00 \\
\hline
\end{tabular}

within parenthesis are percentages over grand total \#(10 out of 19 were solitary and rest multinodular among suspicious ones)

129:21. All the subjects had palpable nodule of either

Table-VII

Clinical prediction over FNAC diagnosis by risk categorization $(n=150)$

\begin{tabular}{lccc}
\hline Character (s) & \multicolumn{2}{c}{ P } & \\
\cline { 2 - 3 } & Benign & Malignant & \\
\hline Low risk group & $90(72.6)$ & $6(23.1)$ & $<001$ \\
Moderate or & $34(27.4)$ & $20(76.9)$ & $<001$ \\
high risk group & & & \\
\hline
\end{tabular}


Table-VIII

Multiple regression analysis for cellular character of

\begin{tabular}{lcc}
\multicolumn{3}{c}{ thyroid nodules } \\
\hline Variable(s) & $\beta$ & $\mathrm{p}$ \\
\hline Constant & & 0.000 \\
Age & -0.090 & 0.240 \\
Sex & 0.023 & 0.763 \\
Recent change in & 0.179 & 0.042 \\
size (increasing) & & \\
Pain in the nodule & & 0.068 \\
& 0.519 & \\
\hline
\end{tabular}

\section{Table-VIII}

Multiple regression analysis for cellular character of thyroid nodules

\begin{tabular}{lcc}
\hline Variable(s) & $\beta$ & $p$ \\
\hline Constant & & 0.000 \\
Age & -0.090 & 0.240 \\
Sex & 0.023 & 0.763 \\
Recent change in & 0.179 & 0.042 \\
size (increasing) & & \\
Pain in the nodule & 0.068 & 0.519 \\
Family history & -0.05 & 0.404 \\
Size of the nodule & -0.072 & 0.398 \\
Solitary or MNG & -0.063 & 0.417 \\
Tenderness & -0.145 & 0.169 \\
Presence of & 0.410 & 0.000 \\
lymph node & & 0.039 \\
Thyroid scan & 0.002 & 0.981 \\
Rapid growth & 0.042 & \\
Diameter & 0.178 & \\
of nodule $(>4 \mathrm{~cm})$ & & \\
\hline & & \\
\hline
\end{tabular}

Table -IX

Malignancy in context to characters of nodules $(N=150)$

\begin{tabular}{lcc}
\hline Characteristics & $\begin{array}{c}\text { Frequency } \\
(\mathrm{n} / \mathrm{N}, \% \\
\text { over total } \\
\text { patients })\end{array}$ & $\begin{array}{c}\text { Malignancy } \\
(\% \text { over } \\
\text { row } \\
\text { frequency) }\end{array}$ \\
\hline Increasing in size & $22(33.0)$ & $10(45.45)$ \\
Enlarged lymph node & $19(28.5)$ & $6(31.57)$ \\
Size of the nodule $(>4 \mathrm{~cm})$ & $16(24.0)$ & $5(31.25)$ \\
All of the three characters & $2(1.3)$ & $2(100)$ \\
present & & \\
\hline
\end{tabular}

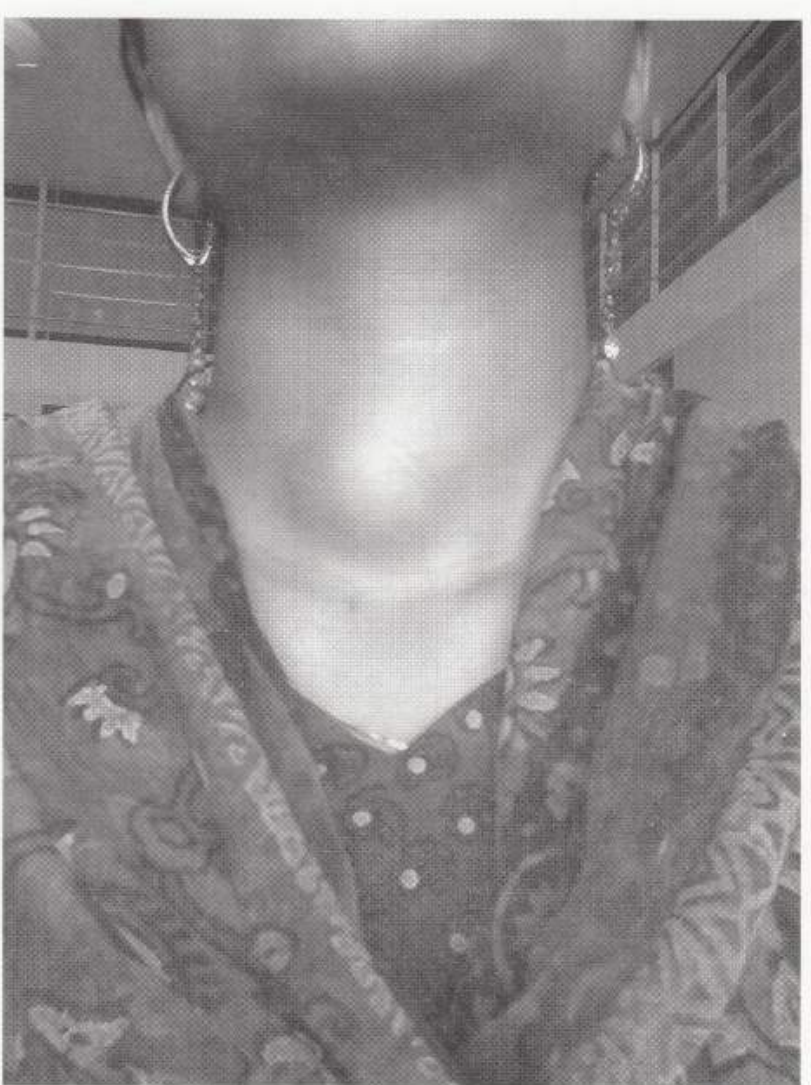

Fig-1. A goiter over the isthmus.

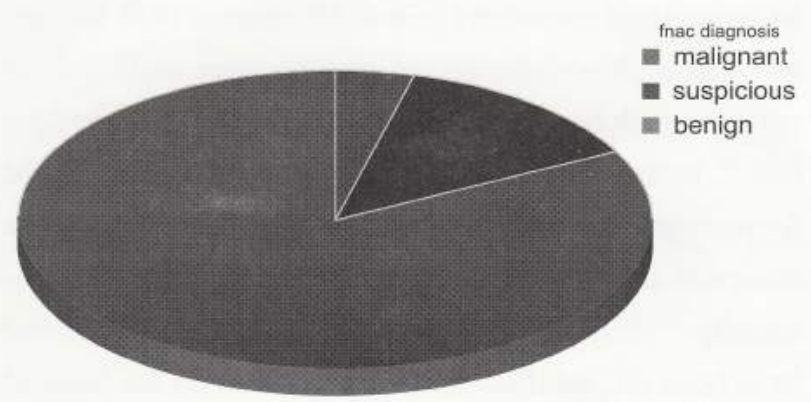

Fig-2. FNAC diagnosis of the thyroid nodules. 


\section{Discussion:}

Cytological diagnosis of thyroid nodule is the gold standard for making decision regarding the potential of a nodule for malignancy. It is better to discriminate the cytological character of a nodule by excision biopsy. However, on consideration of the surgical hazards and financial strain the alternative procedure is FNAC for thyroid nodules to discern the cellular characters is also widely accepted and it yields near similar result with the excision biopsy ${ }^{18}$. Conventionally it is believed that solitary cold nodules are more prone to develop malignancy.

The present study was designed to investigate frequency of malignancy and cellular aberration in thyroid nodules by using the FNAC method in light of clinical suspicion for malignancy in 150 euthyroid subjects with mean ( \pm $\mathrm{SD})$ age of $37 \pm 12$ years and sex ratio (female: male) solitary or multi-nodular variety. It was revealed that about $17 \%$ of the studied nodules harbor cellular aberration and of the total studied nodules about $5 \%$ were clearly identified to be malignant. The proportion of solitary and multinodular goiter were approximately $1: 1$ in case of both malignant and suspicious nodules, which is consistent with the findings of some other investigators ${ }^{10}$, 17, 18. It was also noted that malignant and suspicious nodules significantly correlated with the suspicion of moderate to high risk groups of clinically suspected nodules for cellular aberration. Thus it is clearly apparent that cellular diagnosis of thyroid nodule seems imperative in discriminating the malignant potential of any nodule irrespective of the clinical suspicion.

It is interesting to note here that about $50 \%$ of both malignant (out of 7 patients 4 had solitary and 3 had multinodular goiter) and suspicious (out of 19 patients 10 in solitary and 9 in multinodular goiter) nodules were multinodular variety which is similar to the findings of other investigators ${ }^{18}$. In this context it should be mentioned that highest frequencies of malignant and suspicious cellularity were observed among the cold nodules as is thought conventionally ${ }^{13,18}$. However, about $23 \%$ of the nodules would have been missed their cellular aberration on the basis of risk categorization unless FNAC was done. Highest frequencies of nodules were partially cold; and a good number among them were of suspicious category.

About $50 \%$ of the nodules are multinodular variety. As is mentioned above, contrary to the conventional thought, multinodular goiter does not necessarily mean low potential for malignancy. Rather risk stratification on the basis of clinical points has a strong predictive influence over the cellular character of the nodules ${ }^{17}$. Thus FNAC has a big impact on the decision of cellular character of thyroid nodules which is important clinically for further management of the patients. Apropos with this, other investigators also have emphasized over the impact of FNAC in cellular diagnosis of thyroid nodules ${ }^{22,23,24}$.

It was observed that some of the patients had recent change of size of nodules and some others had associated dysphagia and tenderness. By multiple regression analysis it was observed that presence of enlarged local lymph nodes, increased diameter of thyroid nodules as well as recent changes of the size of the thyroid nodules were independently and significantly related to the possibility of aberrant cellular character of the nodules. There are reports by others who have observed similar findings with thyroid nodules ${ }^{22,23,24}$. Though there is a male preponderance for malignancy in thyroid nodules, it was a limitation in the present study to justify this point because of the fact that most of the patients were females and the number of male patients was very limited. This could have been possible if the study would have been extended for a longer duration to encompass a good number of patients of both sexes.

Conventionally it is believed that thyroid nodules with deviation of hormonal function are unlikely to be malignant. As this study did not include any patient with hypoor hyper- thyroidism, it is not possible to comment on this issue. But, it is assumed and proposed that aberration of thyroid function and chance of malignancy in the nodule may not be mutually exclusive. Therefore, unless strongly contraindicated and beyond feasibility, and if the clinical grounds are strong enough to support the suspicion for malignancy, it is wise to perform FNAC to discriminate the cellular character of the thyroid nodules.

In conclusion, the present study has revealed that FNAC 
is a useful and necessary tool for cellular diagnosis of thyroid nodules. Clinical suspicion for malignancy significantly correlates with the FNAC findings. However, a number of clinically low risk categories would have chance of escape the malignant cellular character unless FNAC is done.

\section{Acknowledgements:}

Authors gratefully acknowledge the technical support extended by the Department of Pathology, BSMMU. We thank the colleagues of the Department of Endocrinology, BSMMU for their moral support for the work. Secretarial support for data entry and manuscript writing by the Staffs of Department of Endocrinology, BSMMU is also acknowlwdged. BSMMU for their moral support for the work. Secretarial support for data entry and manuscript writing by the Staffs of Department of Endocrinology, BSMMU is also acknowlwdged.

\section{References:}

1. Mortinens JD, Woolner LB and Bennet WA. Gross and microscopic findings in a clinically normal thyroid gland. J Clin Endocrine Metab1995; 15: 1270.

2. Welker M and Orlov D. Thyroid Nodules, Am Fam Physician 2003; 67:559-566.

3. Alam MN, Haq SA, Ansari MAJ, Karim MA and Das KK. Spectrum of thyroid disorder in IPGMR, Dhaka. Bangladesh J Med $1995 ; 6: 53-58$.

4. Wang C and Crapo LM. The epidemiology of thyroid disease and implications for screening. Endocrinol Metab Clin North Am1997; 26: $189-218$.

5. Safrit HF. 'Thyroid disorders', In: Fitzgerald PA (editor), Handbook of Clinical endocrinology. 1st ed. Jones medical publication, USA, 1986; p122-169.

6. Vander JB, Gastron EA and Ewber TR. 'Significance of nontoxic thyroid nodule'. New Eng J Med 1984; 257: 970-973.

7. Zeissman HA and Thrall JH. Nuclear Medicine. The Requisites. 2nd edition. London: Mosby A Harcourt Health Science Company, 2001; p 369-370.

8. Chowdhury MR, Alam MN, Haq SA, Ansari MAJ, Nahar N, Momtaz S and Karim MA. Effect of suppressive thyroxine therapy on solitary thyroid nodules. Bangladesh Med. Res. Counc. Bull. 1996; 22:93-97.

9. Matheson N (editor). 'The diagnosis of thyroid swelling' In: Recent Advances in Surgery. Churchill - Livingstone, Edinburgh, 1986; p179-196,

10. Cooper DS, Greenspan FS, Ladenson PW. 'The thyroid gland', In: David G Gardner, Dolores Shoback (editors). Greenspan's Basic \& Clinical Endocrinology. 8th ed. The McGraw-Hill Companies, USA, 2007; p267-278.

11. Schlumberger $\mathrm{M}$ and Pacini $\mathrm{F}$ (editors). Thyroid tumors. Third edition, Editions Nucleon, 2006; p11-28.

12. Raza S, Saeed Z, Raza H and Ahmed M. FNAC in the management of solitary thyroid nodule. Professional Med J 2006; 13: 596-603.

13. Rains AJH and Charles VM (editors). Baily's and Love's short practice of surgery. 20th ed. ELBS, London, 1988; p660-693.

14. Baloch ZW, Sack MJ, Yu GH, Livolsi VA, Gupta PK. Fine needle aspiration (FNA) and cytology. Thyroid 2003; 13: 80-86.

15. Baloch ZW, Sack MJ, Yu GH, Livolsi VA and Gupta PK. Fine needle aspiration of thyroid an institutional experience. Thyroid 1998; 8: 65-569.

16. Gharib H. Fine needle aspiration of thyroid nodules advantages limitations and effects. Mayo clin proc 1994; 69: 44-49.

17. Hamming JF, Goslings BM and VAN steenis GJ et al. The value of fine-needle aspiration biopsy in patients with nodular thyroid disease divided into group of suspicion of malignant neoplasm on clinical grounds. Arch Intern Med 1990; 150: 113-116.

18. AACE/AME. Guidelines for clinical practice for the diagnosis and management of thyroid nodules. 2006; vol.12 No.1.

19. Cheung YS, Poon CM, Mak SM, Suen MWM and Leong HT. Fine-needle aspiration cytology of thyroid nodule- how well are we doing? Hong Kong Med J 2007; 13: 12-15.

20. Tollin SR, Mery GM and Jelveh $\mathrm{N}$ et al. The use of fine needle aspiration biopsy under ultra sound guidance to assess the risk of malignancy in patients with multinodular goiter. Thyroid 2000; 10 : 235-241.

21. Ridgway EC. Clinical review 30: Clinician's evaluation of solitary thyroid nodule. J Clin Endocrine Metab 1992; 74: 231-235.

22. Gharib H and Goellner JR. Fine needle aspiration biopsy of the thyroid: an appraisal. Ann Internal Med 1993; 118: 282-289.

23. Chow LS, Gharib H, Goellner JR and Van Heerden JA. Non diagnostic thyroid fine-needle aspiration cytology: management dilemmas. Thyroid 2001; 11: 1147-1151.

24. Caruso D and Mazzaferri EL. Fine needle aspiration biopsy in the management of thyroid nodules. Endocrinologist 1991; 1:194-202. 